Graphical Abstract (for review)

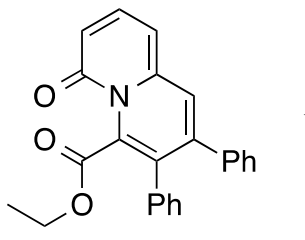

not formed

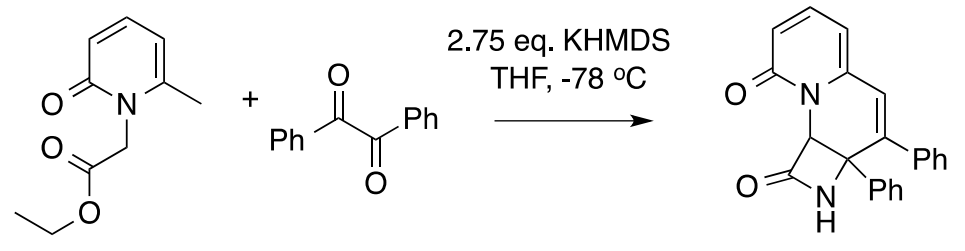

$12 \%$ yield 


\section{Isolation and structure determination of the first example of the azeto[2,3- c]quinolizinedione ring system}

Beatriz Fernandez, ${ }^{\dagger}$ Mark R.J. Elsegood, ${ }^{* \dagger}$ Gary Fairley, ${ }^{\star}$ Gareth J. Pritchard, ${ }^{{ }^{* \dagger}}$ Simon J. Teat $^{\S}$ and George W. Weaver ${ }^{* \dagger}$

†Department of Chemistry, Loughborough University, Loughborough LE11 3TU, UK \#AstraZeneca R\&D | Oncology iMed, Darwin Building (310), Cambridge Science Park, Milton Road, Cambridge, CB4 0WG, UK

$\S$ Lawrence Berkeley National Laboratory, Advanced Light Source, University of California Berkeley, Berkeley, CA 94720, USA

email:m.r.j.elsegood@lboro.ac.uk,g.j.pritchard@lboro.ac.uk, g.w.weaver@lboro.ac.uk

\section{Keywords}

$\beta$-lactam

quinolizinone

pyridone

drug scaffolds

\section{Abstract}

An unexpected azeto[2,3-c]quinolizinedione has been isolated during synthetic studies on the base catalyzed condensation of ethyl 6-methylpyridin-2(1H)-on-1-ylacetate with benzil. Closure of a fused four-membered azetidinone ring occurred when potassium hexamethyldisilazide was employed as the base. The structure of the product was confirmed by synchrotron X-ray crystallography. A possible mechanism for the formation of the product is considered.

\section{Introduction}

4H-Quinolizin-4-one ${ }^{1} 1$ and $2 H$-quinolizin-2-one 2 (Figure 1) represent neutral carbonylbearing derivatives of the quinolizinium ring $^{3}$ system 3 , a bridgehead azanaphthalene. Such compounds have potential application in drug development as alternatives to quinoline $\mathbf{4}$ and isoquinoline $\mathbf{5}$ derivatives, which are much exploited in medicinal chemistry. ${ }^{4}$ 


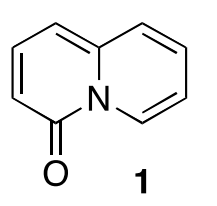<smiles>O=c1ccn2ccccc2c1</smiles>

2<smiles></smiles>

3<smiles>c1ccc2ncccc2c1</smiles>

4<smiles>c1ccc2cnccc2c1</smiles>

5

Figure 1: Azanaphthalene rings employed in medicinal chemistry

A number of quinolizin-4-one based drug candidates have been developed, ${ }^{5,6}$ but considerable scope remains to employ this ring as a central building block in drug discovery. As part of a project to develop synthetic routes to quinolizin-4-ones 1 as new drug scaffolds we investigated the deprotonation of $1(N)$-alkyl-6-methylpyridin-2-ones and the possibility of condensation with 1,2-dicarbonyl compounds to form the second fused pyridine ring. In this paper we report the unexpected formation of an azeto[2,3c]quinolizinedione that was isolated from the reaction of 6 with benzil 7a (Scheme 1).

\section{Results and Discussion}

During a study on the deprotonation of pyridone 6 (Scheme 1) with potassium hexamethyldisilazide (KHMDS), we investigated the reaction with benzil 7a as a 1,2-bis electrophile, using 2.75 equivalents of the base, with the expectation of performing a Westphal-type condensation ${ }^{7}$ to form quinazolin-4-one 8 . However the reaction formed a complex mixture of products, and none of the expected quinolizinone ester $\mathbf{8}$ was obtained after chromatographic separation of the crude reaction mixture. ${ }^{8}$ Surprisingly, the only compound that could be obtained pure was the fused azetidinone $\mathbf{9}$, in which the quinolizin-4-one ring skeleton had formed, but which bore a fused 4-membered lactam ring.
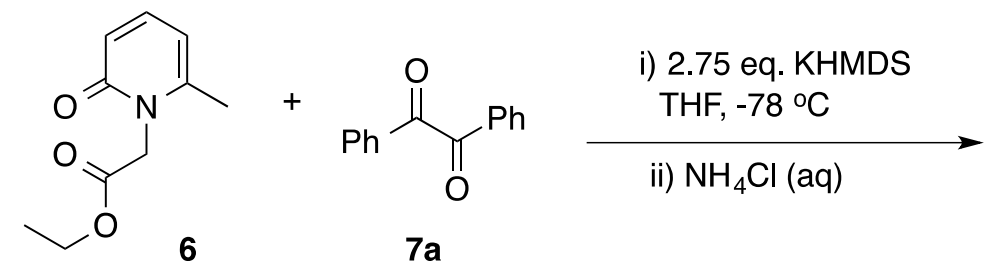

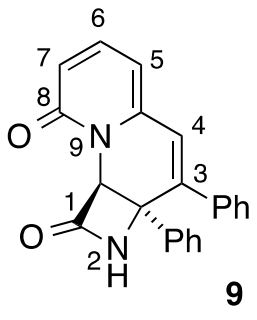

$12 \%$ yield

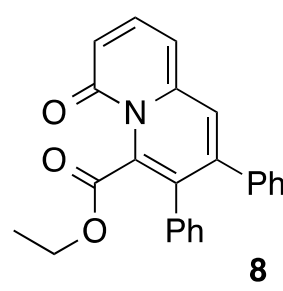

not formed

Scheme 1: Reaction of activated pyridone 6 with benzil

The presence of a 4-membered lactam ring in the molecule was strongly suggested by a 
combination of IR and NMR spectroscopy. In particular, the IR spectrum showed a signal at $1776 \mathrm{~cm}^{-1}$ indicating the presence of a small ring carbonyl group. The ${ }^{1} \mathrm{H}$ NMR spectrum showed an exchangeable signal at $\delta 10.29$ ppm consistent with an $\mathrm{NH}$ and a methine singlet at $\delta 5.86 \mathrm{ppm}(\mathrm{H}-9 \mathrm{a})$. The absence of signals for an ethyl ester indicated that this group had been transformed. The ${ }^{13} \mathrm{C}$ NMR spectrum exhibited a signal at $\delta 68.1$ ppm consistent with a saturated $\mathrm{CH}(\mathrm{C}-9 \mathrm{a})$ and two carbonyl signals at $\delta 164.7$ and 160.5 ppm. The structure of the molecule was verified by single crystal X-ray diffraction analysis, confirming the presence of the 4-membered lactam, which was shown to exist as a monoethanol solvate $\mathbf{9} \cdot \mathrm{EtOH}$ (Figure 2).

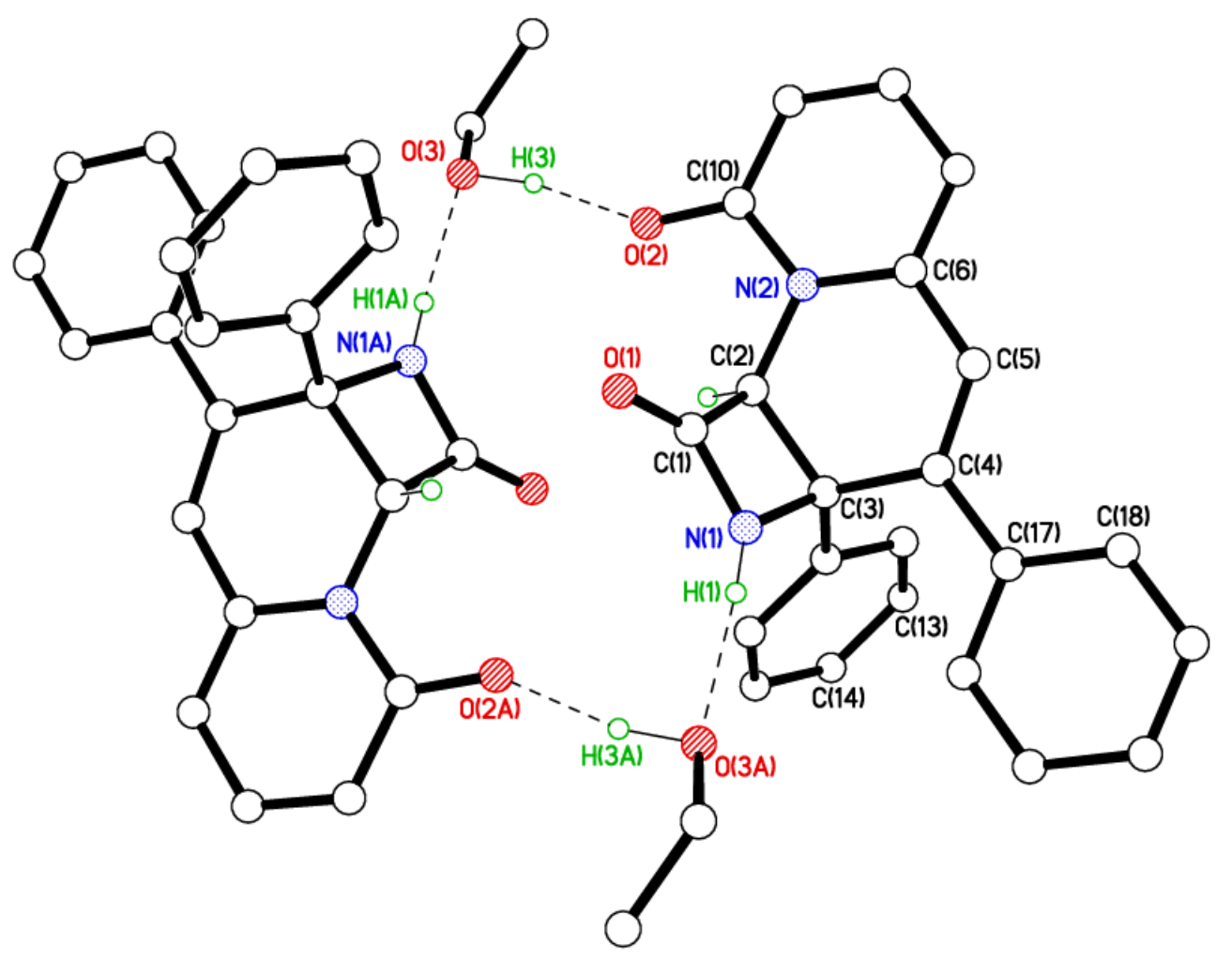

Figure 2: X-ray crystal structure of azeto[2,3-c]quinolizinedione, $\mathbf{9} \cdot \mathrm{EtOH}$, showing the ethanol-inserted hydrogen-bonds between pairs of molecules of $\mathbf{9}$.

Yellow crystals with a plate morphology were formed after slow evaporation of an ethanolic solution of 9. Due to their small size and weak diffracting power, data were collected using synchrotron radiation. ${ }^{9}$ The molecules were found to form head-to-tail $\mathrm{R}_{4}{ }^{4}(18) \mathrm{H}$-bonded pairs via inserted ethanol molecules. ${ }^{10-12}$ The hydrogen bond geometry is given in Table 1.

Table 1. Hydrogen-bond geometry $(\AA \stackrel{\circ}{)})$ for $9 \cdot \mathrm{EtOH}$

\begin{tabular}{|l|l|l|l|l|}
\hline$D-\mathrm{H} \cdots A$ & $D-\mathrm{H}$ & $\mathrm{H} \cdots A$ & $D \cdots A$ & $D-\mathrm{H} \cdots A$ \\
\hline $\mathrm{N} 1-\mathrm{H} 1 \cdots \mathrm{O} 3(\mathrm{~A})$ & $0.92(2)$ & $1.92(2)$ & $2.8305(17)$ & $168(2)$ \\
\hline
\end{tabular}




\begin{tabular}{|l|l|l|l|l|}
\hline $\mathrm{O} 3-\mathrm{H} 3 \cdots \mathrm{O} 2$ & $0.98(3)$ & $1.71(3)$ & $2.6651(16)$ & $165(2)$ \\
\hline
\end{tabular}

Symmetry code: (A) $-x,-y+1,-z+1$.

The formation of the fused azetidinone product 9 was unexpected and several mechanisms for generation of the 4-membered lactam ring compound can be considered. It is not clear how the nitrogen atom of the 4-membered lactam ring was introduced into the molecule, or the order of the ring forming steps. The azetidinone nitrogen is most likely derived from the hexamethyldisilazane (HMDS) formed as a by-product during deprotonation. The most plausible mechanism we propose here (Scheme 2) involves formation of the ester enolate 10 by deprotonation of $\mathbf{6}$ with KHMDS, and reaction of the resulting HMDS, or the excess KHMDS, with benzil $7 \mathbf{a}$ to form either the mono- (7b) or bisimine (7c). Either electrophile could then condense with anion $\mathbf{1 0}$ to form the azetidinone derivative 11. The reaction of imines with ester enolates is a well established method to form medicinally important 4-membered lactams. ${ }^{13}$ Subsequent deprotonation of the 6methyl group of the pyridone ring would generate enolate 12, the cis diastereoisomer of which could undergo intramolecular aldol reaction with the ketone $(X=O)$ or silylimine $(X=$ $\mathrm{NSiMe}_{3}$ ) group forming 13. Subsequent elimination would then generate the observed product $\mathbf{9}$, which was isolated after aqueous work-up.

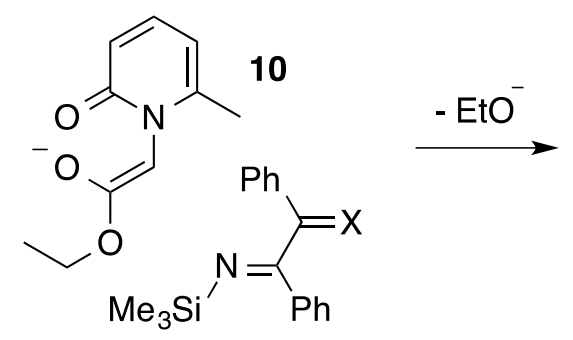

$7 b / c$

b $X=0$

c X $=\mathrm{NSiMe}_{3}$

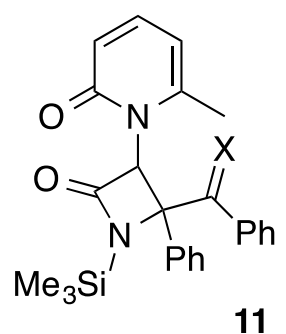

11
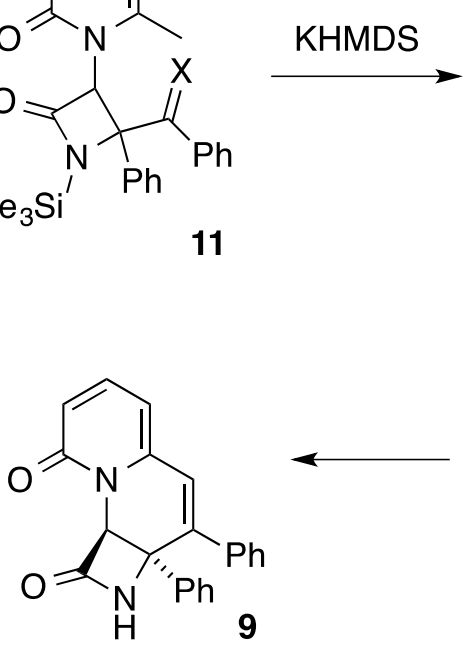

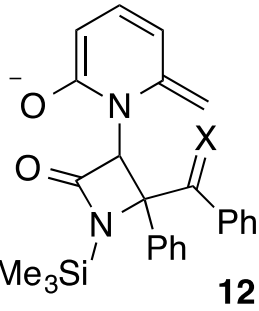

12

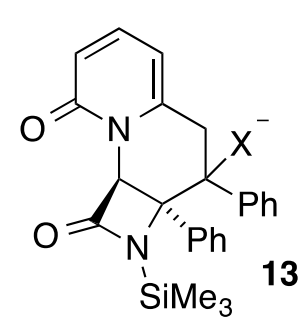

Scheme 2: Possible mechanism for formation of azeto[2,3-c]quinolizine 9

An initial aldol reaction occurring next to the ester group was supported by the observation that deprotonation of 6 with one equivalent of KHMDS and quenching with $\mathrm{D}_{2} \mathrm{O}$ at $-78{ }^{\circ} \mathrm{C}$ led to deuterium incorporation predominantly at the methylene group of the acetate $\left[\delta_{H}\right.$ 
$\left(\mathrm{CD}_{3}\right)_{2} \mathrm{SO} 4.79\left(\mathrm{~s}, \mathrm{CH}_{2}\right), 4.77(\mathrm{bs}, \mathrm{CHD})$ and $\left.\delta_{\mathrm{C}} 43.5\left(\mathrm{CH}_{2}\right), 43.3\left(\mathrm{t}, \mathrm{J}_{\mathrm{CD}}=22 \mathrm{~Hz}, \mathrm{CHD}\right)\right]$ rather than at the pyridone methyl substituent. Other pathways to give 9 can be conceived, and the mechanism of the reaction is under further investigation. Very few examples of compounds in which a $\beta$-lactam ring is fused to an otherwise unsaturated naphthalene type ring are known, ${ }^{14-17}$ and, to the best of our knowledge, none to an unsaturated heterocyclic framework. Compounds of type 9 are likely to exhibit useful biological activity, and further work to improve the yield and scope of this reaction is in progress.

\section{Conclusion}

The first example of a derivative of the tricyclic azeto[2,3-c]quinolizine-1,8-dione ring system has been isolated and its structure confirmed by NMR spectroscopy, mass spectrometry and single crystal synchrotron X-ray diffraction analysis.

\section{Acknowledgements}

We wish to thank the Advanced Light Source for X-ray crystallography. The Advanced Light Source is supported by the Director, Office of Science, Office of Basic Energy Sciences, of the U.S. Department of Energy under Contract No. DE-AC02-05CH11231. We are grateful to the EPSRC National Mass Spectrometry Service Centre, Swansea for mass spectrometric analysis. We thank Mr J. Alastair Daley for technical assistance, $\mathrm{Dr}$ Mark Edgar for NMR spectroscopy, and AstraZeneca and Loughborough University for funding.

\section{Supplementary Data}

Supplementary data showing the ${ }^{1} \mathrm{H}$ and ${ }^{13} \mathrm{C}$ NMR spectra of compound 9 is available.

\section{References}

1. Muir, C.W.; Kennedy, A.R.; Redmond, J.M.; Watson, A.J.B. Org. Biomol. Chem. 2013, 11, 3337-3340.

2. Tynebor, R.M.; Chen, M.H.; Natarajan, S.R.; O'Neill, E.A.; Thompson, J.E.; Fitzgerald, C.E.; O'Keefe, S.J.; Doherty, J.B. Biorg. Med. Chem. Lett. 2010, 20, 2765-2769.

3. Luo, C.-Z.; Gandeepan P.; Cheng, C.-H. Chem. Commun. 2013, 49, 8528-8530.

4. Kettle, J.G.; Brown, S.; Crafter, C.; Davies, B.R.; Dudley, P.; Fairley, G.; Faulder, P.; Fillery, S.; Greenwood, H.; Hawkins, J.; James, M.; Johnson, K.; Lane, C.D.; Pass, M.; Pink, J.H.; Plant, H.; Cosulich, S.C. J. Med. Chem. 2012, 55, 1261-1273.

5. Kuduk, S.D.; Chang, R.K.; Greshock, T.J.; Ray, W.J.; Ma, L.; Wittmann, M.; Seager, 
M.A.; Koeplinger, K.A.; Thompson, C.D.; Hartman, G.D.; Bilodeau, M.T. ACS Med. Chem. Lett. 2012, 3, 1070-1074.

6. Xu, Y.-S.; Zeng, C.-C.; Jiao, Z.-G.; Hu, L.-M.; Zhong, R. Molecules 2009, 14, 868883.

7. Westphal, O.; Jahn, K.; Heffe, W. Arch. Pharm. 1961, 294, 37-45.

8. Experimental procedure for compound 9 2a,3-Diphenyl-2,2a-dihydro-1H-azeto[2,3-c]quinolizine-1,8(9aH)-dione ${ }^{18}$

Ethyl 2-(6-methyl-2-oxopyridin-1 $(2 H)$-yl)acetate $(0.362 \mathrm{~g}, 1.85 \mathrm{mmol})$ and benzil $(0.369 \mathrm{~g}, 1.75 \mathrm{mmol}, 0.95 \mathrm{eq}$.) were dissolved in anhydrous THF $(10 \mathrm{~mL})$ and the mixture was cooled to $-78^{\circ} \mathrm{C}$ and stirred for $10 \mathrm{~min}$. KHMDS ( $0.5 \mathrm{M}$ solution in toluene, $10.2 \mathrm{~mL}, 5.08 \mathrm{mmol}, 2.75$ eq.) was added at $-78^{\circ} \mathrm{C}$ and the mixture was stirred and allowed to warm-up to room temperature overnight. The reaction mixture was treated with saturated aqueous ammonium chloride $(6 \mathrm{~mL})$. The THF was removed under vacuum, and the remaining mixture was extracted with ethyl acetate $(3 \times 25 \mathrm{~mL})$. The combined organic extracts were washed with brine, dried over $\mathrm{MgSO}_{4}$, filtered, and evaporated to afford a dark yellow oil, which was subjected to gradient column chromatography (light petroleum:ethyl acetate) (100:0 to 0:100) to afford $78 \mathrm{mg}$ of a yellow solid. The solid fraction was recrystallized from ethanol to afford the mono-ethanol solvate of the title compound, $80 \mathrm{mg}, 12 \%$ yield, as yellow plate crystals, m.p. $249-250^{\circ} \mathrm{C}, \mathrm{IR}(\mathrm{KBr}) v_{\max } 3350-2700(\mathrm{NH}), 1776(\mathrm{C}=\mathrm{O}), 1654$ $(\mathrm{C}=\mathrm{O}), 1613(\mathrm{C}=\mathrm{C}), 1535(\mathrm{NH}), 795-731$ (CH Arom.) cm ${ }^{-1},{ }^{1} \mathrm{H}(\delta \mathrm{ppm}, 400 \mathrm{MHz}$, DMSO-d $\left.\mathrm{d}_{6}\right) 10.29\left(1 \mathrm{H}, \mathrm{s}\right.$, exchanges with $\left.\mathrm{D}_{2} \mathrm{O}\right), 7.56(1 \mathrm{H}, \mathrm{dd}, J=9.2 \mathrm{~Hz}, J=6.8 \mathrm{~Hz})$, 7.43-7.40 (2H, m), 7.36-7.33 (4H, m), 7.27-7.24 (5H, m), $6.60(1 \mathrm{H}, \mathrm{d}, J=6.8 \mathrm{~Hz})$, $6.45(1 \mathrm{H}, \mathrm{d}, J=9.2 \mathrm{~Hz}), 5.56(1 \mathrm{H}, \mathrm{s}),{ }^{13} \mathrm{C}\left(\delta \mathrm{ppm}, 100 \mathrm{MHz}\right.$, DMSO-d $\left.\mathrm{d}_{6}\right) 164.7$ (C=O), $160.5(\mathrm{C}=\mathrm{O}), 141.7(\mathrm{C}), 140.7(\mathrm{CH}), 140.5(\mathrm{C}), 140.4(\mathrm{C}), 140.3(\mathrm{C}), 135.4$ (C), $129.6(2 \mathrm{CH}), 129.3(\mathrm{CH}), 128.9(2 \mathrm{CH}), 128.4(\mathrm{CH}), 128.0(2 \mathrm{CH}), 125.3(2 \mathrm{CH})$, $120.5(\mathrm{CH}), 120.1(\mathrm{CH}), 108.8(\mathrm{CH}), 68.1(\mathrm{CH}), \mathrm{HRMS}[\mathrm{ES}] \mathrm{m} / \mathrm{z}$ found 341.1286 $(\mathrm{M}+\mathrm{H})^{+} \mathrm{C}_{22} \mathrm{H}_{17} \mathrm{~N}_{2} \mathrm{O}_{2}$ requires 341.1285 .

9. Diffraction data for $\mathbf{9} \cdot \mathrm{EtOH}$ were collected at the Advanced Light Source Station 11.3.1 using silicon 111 monochromated, synchrotron X-radiation on a Bruker Apex 2 CCD diffractometer. ${ }^{19}$ Data were corrected for Lp effects and for absorption, based on repeated and symmetry equivalent reflections, and solved by direct methods. ${ }^{20}$ Structures were solved by direct methods and refined by full matrix least squares on $F^{2} .{ }^{20}$ All non- $\mathrm{H}$ atoms were refined anisotropically. $\mathrm{H}$ atom positions and $U_{\text {iso }}$ values were freely refined. The structure refinement was routine. 
$\mathrm{C}_{22} \mathrm{H}_{16} \mathrm{~N}_{2} \mathrm{O}_{2} \cdot \mathrm{C}_{2} \mathrm{H}_{6} \mathrm{O}, M=386.43$, triclinic, $a=9.106(3), b=9.418(3), c=11.674(4)$ $\AA, \alpha=84.373(5), \beta=85.471(5), \gamma=72.114(5)^{\circ}, U=946.9(5) \AA^{3}, T=100(2) \mathrm{K}$, space group $P \overline{1}, Z=2, \lambda=0.7749 \AA, \mu=0.11 \mathrm{~mm}^{-1}, 12999$ reflections measured, 5677 unique $\left(R_{\text {int }}=0.050\right), R 1$ for 4237 data with $\triangleright 2 \sigma(I)=0.055$, wR2 for all data $=$ 0.157 .

CCDC 1400522 contains the supplementary crystallographic data for this paper. These data can be obtained free of charge from The Cambridge Crystallographic Data Centre via www.ccdc.cam.ac.uk/data_request/cif.

10. Etter, M.C.; MacDonald, J.C.; Bernstein, J. Acta Crystallogr. 1990, B46, 256-262.

11. Etter, M.C. Acc. Chem. Res. 1990, 23, 120-126.

12. Bernstein, J.; Davis, R.E.; Shimoni, L.; Chang, N.-L. Angew Chem., Int, Ed. Engl. 1995, 34, 1555-1573.

13. Hart, D.J.; Ha, D.-C. Chem. Rev, 1989, 89, 1447-1465.

14. Paquette, L.A.; Kakihana, T.; Kelly, J.F. J. Org. Chem. 1971, 36, 435-442.

15. Zoghbi, M.; Warkentin, J. Can. J. Chem. 1992, 70, 2967-2971.

16. Shimano, M.; Meyers, A.I. J. Org. Chem., 1995, 60, 7445-7455.

17 Nowak, M.; Malinowski, Z.; Jozwiak, A.; Fornal, E.; Blaszczsky, A.; Kontek, R. Tetrahedron 2014, 70, 5153-5160.

18. Alternative name: 5,6-diphenyl-1,4-diazatricyclo[6.4.0.0 $\left.0^{2,5}\right]$ dodeca-6,8,10-triene-312-dione.

19. APEX 2 and SAINT (2010) software for CCD diffractometers. Bruker AXS Inc., Madison, USA.

20. Sheldrick, G.M. Acta Cryst. 2015, C71, 3-8. 